\title{
Seropositivity to dengue and associated risk factors among non-malarias acute febrile patients in Arba Minch districts, southern Ethiopia
}

Daniel Eshetu ${ }^{1,2^{*}}$ D, Techalew Shimelis ${ }^{3}$, Eshetu Nigussie ${ }^{2,4}$, Girma Shumie ${ }^{2}$, Wakwoya Chali ${ }^{2}$, Biruck Yeshitela ${ }^{2}$, Abraham Assefa ${ }^{2}$ and Endalamaw Gadisa ${ }^{2}$

\begin{abstract}
Background: Dengue fever is an arthropod vector-borne disease transmitted to humans by infected Aedes mosquitoes. Ethiopia has a favorable ecology for arthropods and report high burden of acute febrile illnesses. However, the contribution of arboviral infections to the burden of acute febrile illnesses is barely known. In this study the seropositivity to dengue virus infection and associated risk factors were assessed in Arba Minch districts, southern Ethiopia.

Methods: An institution based cross-sectional study was conducted in a consecutive group of 529 acute febrile patients between May to August 2016. Socio-demographic data, residence place and clinical signs and symptoms were collected using structured questionnaires. Sera were tested for anti-dengue lgG and IgM using Euroimmune indirect immunofluorescent assay. Data analysis was done using SPSS V-20 (IBM Corp, 2012). P-value < 0.05 was taken as statistically significant.

Result: Seropositivity was $25.1 \%$ (133/529) and 8.1\% (43/529) for anti- IgG and IgM respectively.

Conclusion: The high IgM prevalence detected indicate the probability of active transmission with a potential of public health significance that calls for a proactive follow up of the communities in the study area to forecast and avert the risk.
\end{abstract}

Keywords: Febrile illness, Dengue virus, Seroprevalence, Immunofluorescence

\section{Background}

Dengue fever is an infectious disease and endemic in many countries of the world, is a (re) emerging infection $[1,2]$. The past decades, witnessed a sharp increase in incidence, with estimated 390 million infection and 500, 000 hospitalizations related with the potentially life

\footnotetext{
*Correspondence: danieshetu@gmail.com; danieshetu@gmail.com 'Department of Microbiology, Yirgalem Medical College, Yirgalem, Ethiopia ${ }^{2}$ Malaria-NTD Research Directorate, Armauer Hansen Research Institute, Addis Ababa, Ethiopia

Full list of author information is available at the end of the article
}

threating severe form per year. About 20-25, 000, mainly in children, dengue virus (DENV) infection associated deaths occur each year [3].

The recorded history of DENV in Africa is traced as far back as 1926; having caused an epidemic in Durban, South Africa [4]. Like the global trend, in Africa epidemics of dengue increased drastically since 1980 [5]. Outbreaks were reported in more countries in Africa including Cape Verde, Cote d'Ivoire, Gabon, Senegal, Djibouti, Kenya and Sudan between 2009 and 2012 [6]. Most recently in 2013, Africa recorded DENV outbreaks

(c) The Author(s). 2020 Open Access This article is licensed under a Creative Commons Attribution 4.0 International License, which permits use, sharing, adaptation, distribution and reproduction in any medium or format, as long as you give appropriate credit to the original author(s) and the source, provide a link to the Creative Commons licence, and indicate if changes were made. The images or other third party material in this article are included in the article's Creative Commons licence, unless indicated otherwise in a credit line to the material. If material is not included in the article's Creative Commons licence and your intended use is not permitted by statutory regulation or exceeds the permitted use, you will need to obtain permission directly from the copyright holder. To view a copy of this licence, visit http://creativecommons.org/licenses/by/4.0/ The Creative Commons Public Domain Dedication waiver (http://creativecommons.org/publicdomain/zero/1.0/) applies to the data made available in this article, unless otherwise stated in a credit line to the data. 
in Angola, Kenya, Seychelles and Tanzania [7]. Since the first outbreak in Ethiopia (2013/14) that occurred in Dire Dawa town, areas with similar ecological features, Ada'ar in Afar (2014) regional state and Gode town in Somali (2014 and 2015) regional state had outbreaks [8]. Despite, the increased threat and repeated outbreaks in wide geographical settings, the epidemiology and public health significance of DENV is barely documented in Ethiopia.

DENV infection induces only partial immunity which confers transient protection against subsequent infection by other serotypes [9]. On the basis of severity, the disease is grouped into probable dengue and severe dengue [10]. Probable dengue patient is, a patient either lived in endemic area or had history of travel to endemic areas, such patient may have symptoms like fever, rash, headache, persistent vomiting, mucosal bleed, abdominal pain/tenderness, restlessness, liver enlargement and increased in hematocrit value with decreased in platelet count [11]. In Severe dengue, the patient may have symptoms like severe plasma leakage, fluid accumulation (ascites), respiratory distress; severe bleeding and organ involvement (like liver, CNS and heart) leading to dengue shock syndrome (DSS) and DHF [12] with a mortality rate up to $26 \%$ [13].

The laboratory methods for the diagnosis of DENV infection include virus isolation, and detection of viral $\mathrm{Nu}$ cleic acid, Antigen and anti-DENV antibodies (serology). The serologic detection of IgM and IgG antibodies by ELISA (Enzyme-linked immunosorbent assay) and IFA (Indirect immunofluorescence assay) platforms [14].

Despite the high burden of acute febrile illness in southern Ethiopia (SNNPR, Southern Nations Nationalities Peoples Regional state Health Bureau report 2014/ 150) and outbreaks in other parts of the country, the impact of DENV infection remain unnoticed. Thus, this study aimed to assess the prevalence of the exposure and its associated risk factors among non-malaria acute febrile patients in Arba Minch districts, SNNPR, southern Ethiopia.

\section{Methods}

Consecutive self-reported volunteers at the outpatient departments of selected health centers were recruited from May to August 2016 in Arbaminch district. The district is located in the southern part of Ethiopia, with climatic condition of semi-desert and means annual rain fall $1300.5 \mathrm{~mm}$. Three selected health centers (Lante Health Center, Shele Health Center and Birbir Health Center) were included in the study. Those sites were selected based on reports of higher rate of febrile illness (Personal communication with Health Bureau of SNNP $\mathrm{R})$. Five hundred twenty-nine non-malaria acute febrile patients, $37.5^{\circ} \mathrm{C}$ axillary temperature at initial evaluation and less than 7 days of onset of symptoms, at the specified health facilities were enrolled.

Structured questionnaires were used to capture data on clinical signs, symptoms and socio-demographic related risk factors. Five $\mathrm{ml}$ of venous blood was collected aseptically from each study participant and the serum sample was separated into multiple Nunc tubes for each patient then transported using liquid nitrogen and stored in deep freezers $\left(-80^{\circ} \mathrm{C}\right)$ until screened for anti-dengue IgG and IgM using IIFT (Indirect Immune Fluorescent Test). The test was carried out according to the directions of the manufacturers.

Data collected with questionnaires and laboratory investigations were double entered in REDCap data software to control error and analyzed using SPSS version 20. Study findings were explained in words and tables. In Bivariate analysis, variables that were found to have association with the outcome variable at $P$-value of 0.25 were entered into multivariable logistic regression to assess the relationship between socio-demographic and other relevant variables with dengue virus sero-status. Associations between dependent and independent variables were assessed and its strength was described using odds ratios and 95\% confidence intervals. P-value less than 0.05 were interpreted as statistically significant.

\section{Results}

Of the 529 acute febrile cases, participants within the age group $15-30$ years accounted $47.45 \%$, followed by age group between 31 and 45 years 19.86\%. Of the study participants, $39.9 \%$ had only primary school level education, $29.0 \%$ had secondary and higher grade completed and $31.1 \%$ had no formal education. Most study participants $(86.8 \%)$ were rural residents (Table 1$)$. The seroprevalence of dengue was $25.1 \%$ (133/529) for IgG and $8.1 \%(42 / 529)$ for IgM (Table 1$)$.

The seropositivity of resent mosquito bites $25.2 . \%$ and 6.6, habit of staying outside at the night 19.5 and $5.7 \%$, use of bed-net at previous night 17.8 and $6.1 \%$, and presence of stagnant water in the village $8.1 \%$ and $2,7 \% \operatorname{IgG}$ and IgM respectively. However, there was no statistically significant association between those associated factors and dengue virus infection (Table 2).

The exposure of dengue virus infection in relation to different clinical factors is summarized in (Table 3). Majority $21.2 \%$ and $2,7 \%$ of the study participants had constitutional symptoms, followed by high body temperature 11.9 and $3.4 \%$ then Headache 8.1 and $2.1 \%$ for IgG and IgM respectively. Other clinical features that the study participants experienced include: sore throat 7.2 and $4.0 \%$, crepitation 3.6 and $1.5 \%$, flank pain 1.9 and $0.8 \%$, flank pain 1.9 and $0.6 \%$, abnormal heart sound 1.5 and $0.6 \%$, rash 1.1 and $0.4 \%$, blurred vision 0.8 and $0.4 \%$, neck stiffness $0.6 \%$ and $0,2 \%$, musculoskeletal 
Table 1 The prevalence of exposure Dengue virus $(N=529)$ by socio-demography and residence place in Arba Minch districts southern Ethiopia, 2016

\begin{tabular}{|c|c|c|c|c|c|c|c|}
\hline \multirow[t]{2}{*}{ Variables } & \multirow[t]{2}{*}{ Total (\%) } & \multicolumn{2}{|c|}{ lgG Test n (\%) } & \multicolumn{2}{|c|}{ IgM Test n (\%) } & \multicolumn{2}{|l|}{ COR $(95 \% \mathrm{Cl})$} \\
\hline & & $\operatorname{lgG}+V e$ & $\lg G-V e$ & $\lg M+V e$ & $\lg M-V e$ & IgG Test & IgM Test \\
\hline \multicolumn{8}{|l|}{ Sex } \\
\hline Male & $226(42.7)$ & $61(11.5)$ & $165(31.2)$ & $16(3.2)$ & $210(39.7)$ & 1 & 1 \\
\hline Female & $303(57.3)$ & 72 (13.6) & $231(43.7)$ & $26(4.9)$ & $277(52.4)$ & $0.8(0.6-1.3)$ & $1.2(0.6-2.4)$ \\
\hline \multicolumn{8}{|l|}{ Age group } \\
\hline$<15$ yrs & $80(15.13)$ & $25(4.7)$ & $55(10.4)$ & $9(1.7)$ & $71(13.4)$ & 1 & 1 \\
\hline $15-30$ & $251(47.5)$ & $61(11.5)$ & $190(35.9)$ & $21(4.0)$ & $230(43.5)$ & $0.3(0.2-1.1)$ & $0.3(0.3-1.9)$ \\
\hline $31-45$ & $105(19.9)$ & $28(5.3)$ & 77 (14.6) & $8(1.5)$ & $97(18.4)$ & $0.3(0.4-1.7)$ & $0.4(0.4-1.8)$ \\
\hline$>45$ & $93(17.6)$ & $19(3.6)$ & $74(14.0)$ & $4(0.8)$ & 89 (16.8) & $1.6(0.8-3.1)$ & $1.4(0.7-2.9)$ \\
\hline \multicolumn{8}{|l|}{ Residence } \\
\hline Rural & $459(86.8)$ & $113(21.4)$ & $346(65.4)$ & $34(6.4)$ & $425(80.4)$ & $0.8(0.5-1.4)$ & $0.6(0.3-1.4)$ \\
\hline Urban & 70 (13.2) & $20(3.8)$ & $50(9.4)$ & $8(1.5)$ & $62(11.7)$ & 1 & 1 \\
\hline
\end{tabular}

tenderness $0.6 \%$ and $0,2 \%$, hearing loss 0.2 and $0 \%$ (Table 3).

In bivariate analysis, candidate variables like: Ear symptoms, Diarrhea, high body temperature and constitutional symptoms, also occupation like employee, student and age group between 31 and 45 years and age group $>45$ years are selected. To avoid the possible confounding variables that found to have association with the dengue virus at $P$-value of 0.25 by bivariate were entered into multivariate logistic regression. Only constitutional symptoms remain significant $(\mathrm{OR}=1.71 ; 95 \% \mathrm{CI}$ $1.015-2.870 ; p<0.044)$; of 112 who had constitutional symptoms and positive $10.0 \%$ had only acute fever, $7.5 \%$ had acute fever and fatigue, $19.4 \%$ had fever and loss of appetite, $31.3 \%$ had fever, fatigue and loss of appetite, and $1.7 \%$ had acute fever, loss of appetite and night sweeting.

\section{Discussion}

The finding of this study shows, the overall seroposetivity of dengue virus exposure in this study was $25.1 \%$ for IgG and $8.1 \%$ for IgM. The distribution of dengue seropositivity rate among the study population in the 3 health facilities was comparable. This suggests that the risk of being infected by dengue is relatively homogenous within the populations from each health facility. Direct comparison between different findings may be difficult due to methodological difference, diagnostic tools employed and study population investigated. This finding is comparable to the rate $(27.7 \%)$ that reported

Table 2 Dengue virus infection in relation to risk factors in febrile patients $(N=529)$ in Arba Minch districts in southern Ethiopia, 2016

\begin{tabular}{|c|c|c|c|c|c|c|c|}
\hline \multirow[t]{2}{*}{ Variables } & \multirow{2}{*}{$\begin{array}{l}\text { Total N } \\
(\%)\end{array}$} & \multicolumn{2}{|c|}{ lgG test $\mathrm{n}(\%)$} & \multicolumn{2}{|c|}{ lgM test n (\%) } & \multicolumn{2}{|l|}{ COR $(95 \% \mathrm{Cl})$} \\
\hline & & $\lg G+V e$ & $\lg G-V e$ & $\lg M+V e$ & $\lg M-V e$ & lgG test & lgM test \\
\hline \multicolumn{8}{|c|}{$\begin{array}{l}\text { Use of bed-net } \\
\text { at previous night }\end{array}$} \\
\hline Yes & $360(68.1)$ & $94(17.8)$ & $266(50.3)$ & $32(6.1)$ & $328(62.0)$ & $0.9(0.6-1.3)$ & $1.6(0.7-3.2)$ \\
\hline No & $169(31.9)$ & $39(7.4)$ & $130(24.5)$ & $10(1.9)$ & $159(30.1)$ & 1 & 1 \\
\hline \multicolumn{8}{|c|}{$\begin{array}{l}\text { Presence of stagnant } \\
\text { water in the village }\end{array}$} \\
\hline Yes & $172(32.5)$ & $43(8.1)$ & $129(24.4)$ & $14(2.7)$ & $158(29.9)$ & 1 & 1 \\
\hline No & $357(67.5)$ & $90(17.0)$ & $267(50.5)$ & $28(5.3)$ & $329(62.2)$ & $1.0(0.7-1.5)$ & $1.0(0.5-2.0)$ \\
\hline \multicolumn{8}{|c|}{ Habit of staying outside at the night } \\
\hline Yes & $414(78.3)$ & $103(19.5)$ & $311(58.8)$ & $30(5.7)$ & $384(72.6)$ & $1.1(0.7-1.7)$ & $0.7(0.3-1.4)$ \\
\hline No & $115(21.7)$ & $30(5.7)$ & $85(16.0)$ & $12(2.3)$ & $103(19.5)$ & 1 & 1 \\
\hline \multicolumn{8}{|c|}{ Resent mosquito bite } \\
\hline Yes & $246(46.5)$ & $62(25.2)$ & $184(21.3)$ & $35(6.6)$ & $211(39.9)$ & $1.0(0.6-1.7)$ & $1.0(0.4-2.2)$ \\
\hline No & $283(53.5)$ & $71(25.1)$ & $212(28.4)$ & $7(1.3)$ & $276(52.2)$ & 1 & 1 \\
\hline
\end{tabular}


Table 3 Dengue virus infection in relation to clinical features in febrile patient in Arbaminch Districts in southern Ethiopia, 2016

\begin{tabular}{|c|c|c|c|c|c|c|c|}
\hline \multirow[t]{2}{*}{ Variables } & \multirow{2}{*}{$\begin{array}{l}\text { Total } \\
\mathrm{N}(\%)\end{array}$} & \multicolumn{2}{|c|}{ lgG test $n(\%)$} & \multicolumn{2}{|c|}{ lgM test $\mathrm{n}(\%)$} & \multicolumn{2}{|l|}{ COR $(95 \% \mathrm{Cl})$} \\
\hline & & $\operatorname{lgG}+V e$ & $\lg G-V e$ & $\lg M+V e$ & $\lg M-V e$ & $\operatorname{lgG}$ test & lgM test \\
\hline \multicolumn{8}{|c|}{ Head signs (scalp lesion) } \\
\hline Yes & $17(3.2)$ & $4(0.8)$ & $13(2.4)$ & $0(0)$ & $17(3.2)$ & 1 & 1 \\
\hline No & $512(96.8)$ & $129(24.4)$ & $383(72.4)$ & $42(8.0)$ & $470(88.9)$ & $1.1(0.4-3.4)$ & $0.92(2.9)$ \\
\hline \multicolumn{8}{|c|}{ Neck signs (neck stiffness) } \\
\hline Yes & $20(3.8)$ & $3(0.6)$ & $17(3.2)$ & $1(0.2)$ & $19(3.6)$ & 1 & 1 \\
\hline No & $509(96.2)$ & $130(24.6)$ & $379(71.6)$ & $41(7.8)$ & $468(88.5)$ & $0.9(0.2-3.4)$ & $1.2(0.2-9.3)$ \\
\hline \multicolumn{8}{|c|}{ Eye symptoms (blurred vision) } \\
\hline Yes & $61(11.5)$ & $4(0.8)$ & $57(10.7)$ & $2(0.4)$ & $59(11.2)$ & 1 & 1 \\
\hline No & $468(88.5)$ & $129(24.4)$ & $339(64.1)$ & $40(7.6)$ & $428(80.9)$ & $1.5(0.5-4.6)$ & $0.5(0.1-4.1)$ \\
\hline \multicolumn{8}{|c|}{ Ear symptoms (hearing loss) } \\
\hline Yes & $9(1.7)$ & $1(0.2)$ & $8(1.5)$ & $0(0)$ & $9(1.7)$ & 1 & 1 \\
\hline No & $520(98.3)$ & $132(25.0)$ & $388(73.3)$ & $42(7.9)$ & $478(90.4)$ & $0.2(0.0-1.9) *$ & $1.0(0.1-8.2)^{*}$ \\
\hline \multicolumn{8}{|c|}{ Mouth and Throat (sore throat) } \\
\hline Yes & $59(11.2)$ & $38(7.2)$ & $21(4.0)$ & $14(2.7)$ & $45(8.5)$ & 1 & 1 \\
\hline No & $470(88.8)$ & $95(18.0)$ & $375(70.8)$ & $28(5.3)$ & $442(83.6)$ & $0.9(0.5-1.3)$ & $0.7(0.4-1.3)$ \\
\hline \multicolumn{8}{|c|}{ Nose sign (nose bleeding) } \\
\hline Yes & $25(4.7)$ & $9(1.7)$ & $16(3.0)$ & $3(0.6)$ & $22(4.2)$ & 1 & 1 \\
\hline No & $504(95.3)$ & $124(23.4)$ & $380(71.9)$ & $39(7.4)$ & $465(87.9)$ & $1.2(0.5-2.6)$ & $2.8(0.4-20.9)$ \\
\hline \multicolumn{8}{|c|}{ Chest exam signs (crepitation) } \\
\hline Yes & $29(5.5)$ & $19(3.6)$ & $10(1.9)$ & $8(1.5)$ & $21(4.0)$ & 1 & 1 \\
\hline No & $500(94.5)$ & $114(21.6)$ & $386(72.9)$ & $34(6.4)$ & $466(88.1)$ & $0.7(0.1-6.7)$ & $0.6(0.3-1.4)$ \\
\hline \multicolumn{8}{|c|}{ Cardiovascular signs (abnormal heart sound) } \\
\hline Yes & $30(5.7)$ & $8(1.5)$ & $22(4.2)$ & $2(0.4)$ & $28(5.3)$ & 1 & 1 \\
\hline No & $499(94.3)$ & $125(23.6)$ & $374(70.7)$ & $40(7.6)$ & $459(86.8)$ & $1.1(0.5-2.5)$ & $1.1(0.2-1.1)$ \\
\hline \multicolumn{8}{|c|}{ Abdominal signs (enlarged liver) } \\
\hline Yes & $43(8.1)$ & $10(1.9)$ & $33(6.2)$ & $3(0.6)$ & $40(7.56)$ & 1 & 1 \\
\hline No & $486(91.9)$ & $123(23.3)$ & $363(68.6)$ & $39(7.4)$ & $447(84.5)$ & $1.3(0.6-2.7)$ & $0.8(0.2-2.6)$ \\
\hline \multicolumn{8}{|c|}{ Urination symptoms (flank pain) } \\
\hline Yes & $43(8.1)$ & $10(1.9)$ & $33(6.2)$ & $4(0.8)$ & $39(7.4)$ & 1 & 1 \\
\hline No & $486(91.9)$ & $123(23.3)$ & $363(68.6)$ & $38(7.2)$ & $448(84.7)$ & $1.3(0.6-2.7)$ & $0.6(0.2-1.9)$ \\
\hline \multicolumn{8}{|c|}{ Musculoskeletal Signs (tenderness) } \\
\hline Yes & $15(2.8)$ & $3(0.6)$ & $12(2.2)$ & $1(0.2)$ & $14(2.7)$ & 1 & 1 \\
\hline No & $514(97.2)$ & $130(24.6)$ & $384(72.6)$ & $41(7.8)$ & $473(89.4)$ & $0.7(0.2-2.7)$ & $1.2(0.2-9.5)$ \\
\hline \multicolumn{8}{|c|}{ Dermatological Signs (rash) } \\
\hline Yes & $16(3.0)$ & $6(1.1)$ & $10(1.9)$ & $2(0.4)$ & $14(2.7)$ & 1 & 1 \\
\hline No & $513(97.0)$ & $127(24.0)$ & $386(73.0)$ & $40(7.6)$ & $473(89.4)$ & $1.8(0.7-5.1)$ & $0.6(0.1-2.7)$ \\
\hline \multicolumn{8}{|c|}{ High body Temperature } \\
\hline $37.5-38$ & $284(53.7)$ & $63(11.9)$ & $221(41.8)$ & $18(3.4)$ & $266(50.3)$ & $0.7(0.5-1.1) *$ & $1.6(0.9-3.0) *$ \\
\hline$>38$ & $245(46.3)$ & $70(13.2)$ & $175(33.1)$ & $24(4.5)$ & $221(41.8)$ & 1 & 1 \\
\hline \multicolumn{8}{|l|}{ Headache } \\
\hline Yes & 441 (83.4) & 109 (8.2) & $332(1.4)$ & $11(2.1)$ & $430(81.3)$ & $0.9(0.5-1.5)$ & $0.8(0.3-2.0)$ \\
\hline No & 88 (16.6) & $24(1.8)$ & $64(14.8)$ & $31(5.9)$ & $57(10.8)$ & 1 & 1 \\
\hline
\end{tabular}

\section{Shortness of breath}


Table 3 Dengue virus infection in relation to clinical features in febrile patient in Arbaminch Districts in southern Ethiopia, 2016 (Continued)

\begin{tabular}{|c|c|c|c|c|c|c|c|}
\hline \multirow[t]{2}{*}{ Variables } & \multirow{2}{*}{$\begin{array}{l}\text { Total } \\
\mathrm{N}(\%)\end{array}$} & \multicolumn{2}{|c|}{ lgG test $n(\%)$} & \multicolumn{2}{|c|}{ IgM test $\mathrm{n}(\%)$} & \multicolumn{2}{|l|}{ COR $(95 \% \mathrm{Cl})$} \\
\hline & & $\operatorname{lgG}+V e$ & $\lg G-V e$ & $\lg M+V e$ & $\lg M-V e$ & $\operatorname{lgG}$ test & lgM test \\
\hline Yes & $24(4.5)$ & $13(2.5)$ & $11(2.0)$ & $3(0.6)$ & $21(4.0)$ & 1 & 1 \\
\hline No & $505(95.5)$ & $120(22.7)$ & $385(72.8)$ & $39(7.4)$ & $466(88.1)$ & $1.0(0.40-4.40)$ & $1.0(0.1-8.2)$ \\
\hline \multicolumn{8}{|l|}{ Vomiting } \\
\hline Yes & $85(16.1)$ & $21(4.0)$ & $64(12.1)$ & $6(1.1)$ & 79 (1493) & 1 & 1 \\
\hline No & $444(83.9)$ & $112(21.2)$ & $332(62.7)$ & $36(6.8)$ & $408(77.1)$ & $1.0(0.6-1.7)$ & $1.2(0.5-2.9)$ \\
\hline \multicolumn{8}{|l|}{ Diarrhea } \\
\hline Yes & $45(8.5)$ & $8(1.5)$ & $37(7.0)$ & $2(0.4)$ & $43(8.1)$ & 1 & 1 \\
\hline No & $484(91.5)$ & $125(23.6)$ & $359(67.9)$ & $40(7.6)$ & $444(83.9)$ & $0.6(0.28-1.4)^{*}$ & $1.9(0.5-8.3)^{*}$ \\
\hline \multicolumn{8}{|c|}{ Constitutional symptoms } \\
\hline Yes & $412(77.9)$ & $112(21.2)$ & $300(56.7)$ & $14(2.7)$ & $398(75.2)$ & $1.71(1.0-2.9)^{* *}$ & $1.4(1.1-2.0)^{* *}$ \\
\hline No & $117(22.1)$ & $21(4.0)$ & $96(18.1)$ & $26(4.9)$ & $91(17.2)$ & 1 & 1 \\
\hline
\end{tabular}

COR crude odds ratio; $\mathrm{Cl}$ confidence interval; 1 Reference; * Candidate variable $(p<0.25)$; ** Significant association $(p<0.05)$

from a border state between Sudan and Republic of South Sudan [15]. The current result was also in line with the finding of a study conducted in Djibouti (21.8\%) [16]. However, was lower than the reports from Dire Dawa, Ethiopia [17], in Nigeria [18], in Kenya [19], and in Brazil [19], which were 62.5, 67.7, 67.0 and 56\%, respectively.

On the other hand, the lower rates of seropositivity compared to the current finding were reported in studies done in Kenya [20], in Cameroon [21], in north-west Zambia [22] and in eastern part of Sudan [23],which were $14.4,12.5,4.1$ and $9.4 \%$, respectively. The reason for this difference in prevalence between the previous studies and the current study may be due to various factors. The current study focused on the detection of IgG/ IgM antibodies from acute febrile participants; however, the previous studies focused mainly on detection of IgG antibodies from healthy participants (survey on healthy individuals) or detection of IgG antibodies in dengue outbreak situations. Diagnostic tools also make difference as there is a considerable discrepancy between the performance of indirect ELISA and PRNT (Plague Reduction Neutralization test) [24].

Further, in line with the study result in Texas-Mexico [25], this study showed no association between dengue exposure and utilization of bed net, use of mosquito repellent, presence stagnant water near resident areas and tree in the compound, staying out side at night, or knowledge about the virus. However, in contrast to these findings, a study in Haiti suggested that utilization of bed net might protect people against dengue infection [26]. The lack of association in the current study may be because Aedes aegyptics commonly bites during day time [11], and therefore the use of bed net may not help provide a barrier between humans and the vector.
As a cause of febrile illness, dengue virus infection is characterized by clinical features including high fever, headache, severe myalgia, nausea and vomiting and frequently rash. However, the predominant clinical signs and symptoms of the infection may vary with populations in different geographical regions [27]. It was shown in a study conducted in Kenya that headache; muscle pain, joint pain and abdominal pain were found to be associated with increased rate of dengue virus infection. However, none of those variables were associated with the infection in the current study as was the case in a study done in rural parts of western Kenya [28].

The limitations of this study were its cross-sectional nature and the use of serology (Euroimmune IIFT) test alone to determine the seroposetivity of Dengue virus. Therefore, the findings may not be generalized to the general population in the study area and even if the manufacturer claimed high specify of the test to our knowledge no comparative studies confirming that and thus probability of cross reacting with other arboviral infection could not be ruled out.

\section{Conclusion}

The high IgM prevalence detected indicate the probability of active transmission with a potential of public health significance that calls for a proactive follow up of the communities in the study area to forecast and avert the risk.

\section{Abbreviations}

AHRI: Armauer Hanen Research Institute; DENV: Dengue virus; DF: Dengue Fever; OPD: Outpatient department; ELISA: Enzyme linked immune sorbent assay; RT-PCR: Reverse transcriptase Polymerase chain reaction; IIFA: Indirect immunofluorescence assay; IgG: Immunoglobulin G; IgM: Immunoglobulin M; AFI: Acute febrile illness; PRNT: Plaque reduction neutralization test 


\section{Acknowledgments}

We acknowledge the contribution of the professionals of study health facilities, Hawassa University and AHRI for allowing its laboratory facility fee of charge.

\section{Authors' contributions}

$D E, E G, A A$ and TS designed the study; DE, EN, GS, WC and BY contributed to the laboratory work; DE, EG, AA and TS performed the statistical analyses, interpretation and contributed to the write-up. All authors read and approved the final version of the manuscript.

\section{Funding}

The Ethiopian Federal Ministry of Health through the clinical research network to $E G, A H R I$

\section{Availability of data and materials}

The dataset used for this article is available upon request to Armauer Hansen Research Institute. Written authorization from AHRI/ALERT ethics committee (P.O. Box 1005, Addis Ababa) and Endalamaw Gadisa (Dr) email: endalamaw. gadisa@ahri.gov.et

\section{Ethics approval and consent to participate (IRB/005/08)}

Ethical clearance was obtained from Hawassa University comprehensive specialized Hospital (IRB/005/08 date 26/10/2015) and AHRI/ALERT Ethical Review Committee (PO-36-15) date 01/12/2015. Official permission was also secured from the SNNPR Health Bureau before data collection 48-240/6449 date 15/12/2015. Informed written consent was obtained from the participants or parents/legal guardians for minors, in addition for those between 12 and 18 year informed assent was sought. The confidentiality of the participants' information was strictly preserved.

\section{Consent for publication}

Not applicable.

\section{Competing interests}

The authors declare that they have no competing interests.

\section{Author details}

'Department of Microbiology, Yirgalem Medical College, Yirgalem, Ethiopia. ${ }^{2}$ Malaria-NTD Research Directorate, Armauer Hansen Research Institute, Addis Ababa, Ethiopia. ${ }^{3}$ School of Medical Laboratory Science, Hawassa University, Hawassa, Ethiopia. ${ }^{4}$ Department of Medical Laboratory Science, Madda Walabu University, Bale Goba, Ethiopia.

Received: 28 August 2019 Accepted: 25 August 2020

Published online: 31 August 2020

\section{References}

1. André O.M. Patterns of disease and understanding of prevention, dengue fever in Ribeirão Preto, Brazil, 2014; 2003-2012.

2. Simmons (P, Farrar JJ, Vinh Chau N, Wills B. Dengue. New England J Med. 2012;366(15):1423-32.

3. The European Centre for Disease prevention and control, facts about denque https://www.ecdc.europa.eu/en/dengue-fever/facts/factsheet".

4. Gubler DJ. Dengue hemorrhagic fever: a global update. Virus in Exch News. 1991;8:2-3.

5. Ooi EE, Gubler DJ. Global spread of epidemic dengue: the influence of environmental change. Future Viro. 2009:4:571-80.

6. Caron M, Grard G, Paupy C, Mombo IM, Bi Nso BB, Kassa FRK, Nkoghe D, Leroy EM. First evidence of simultaneous circulation of three different dengue virus serotypes in Africa. PLoS One. 2013;8:e78030.

7. Centers for Disease Control and Prevention. Ongoing dengue epidemic in Angola. Morb Mort Wkly R. 2013;62:504-7.

8. Diriba Sufa Gemechu, Yoseph Worku, Abebe Alemu, Zewdu Assefa Edea et al Fourth Dengue Fever Outbreak Investigation in Ethiopia: A case Control Study 2015.

9. Morens DM. Antibody-dependent enhancement of infection and the pathogenesis of viral disease. Clin Infect Dis. 1994;19:500-12.

10. World health organization. Handbook for Clinical Management of Denque. Geneva: World Health Organization; 2012.
11. Mazaba-Liwewe SS, Monze M, et al. First sero-prevalence of dengue fever specific immunoglobulin $\mathrm{G}$ antibodies in Western and North-Western provinces of Zambia: a population based cross sectional study. Virology J. 2014;11:-135 http://www.virologyj.com/content/11/1/135.

12. Whitethorn J, Farrar J. Dengue. Br Med Bull. 2010;95:161-73.

13. Ranjit S, Kissoon N. Dengue hemorrhagic fever and shock syndromes. Pediatric Care Med. 2011;12:90-100.

14. Borges MC, Passos LMR, Castro-jorge LA, Machado PRL, Favero CA, De Oliveira RM, BAL F. Clinical Evaluation of the NS1 Antigen-Capture by ELISA for Early Diagnosis of Dengue Virus Infection in Brazil. J Med Virol. 2010; 1405:1400-5.

15. Mohammed A, Soghaier SFM, Pasha O, Azam SI, Karsani MM, et al. Dengue fever in a border state between Sudan and Republic of South Sudan: Epidemiological perspectives. J Public Health Epidemiology. 2013;5(8):31924.

16. Andayi F, Andayi F, Charrel RN, Kieffer A, Richet H, Pastorino B, Goffart L. Sero epidemiological Study of Arbovirus Fevers in Djibouti, Horn of Africa. PLoS Negl Trop Dis. 2014;8:12.

17. Honório NA, Nogueira RM, Codeço CT, Carvalho MS, Cruz OG, Magalhães Mde A, Alves FC. Spatial evaluation and modeling of Dengue seroprevalence and vector density in Rio de Janeiro, Brazil; 2009.

18. Baba M, Logue CH, Oderinde B, Abdulmaleek H, Joshua W. Evidence of arbovirus co-infection in suspected febrile malaria and typhoid patients in Nigeria. J Infect Dev Countries. 2013;7(1):051-9.

19. Sutherland LJ, Labeaud AD, Muirur S, Sutherland LJ, Dahir S. Short Report: Serologic Evidence of Arbovirus Infections among Humans in Kenya. Am J Trop Med Hygiene. 2011;85(1):158-61.

20. Malavige GN, Velathanthiri VG, Wijewickrama ES, Fernando S, Jayaratne SD, Aaskov J, Seneviratne SL. Patterns of disease among adults hospitalized with dengue infections. QJM. 2006;99(5):299-305.

21. Mark H, Nathan D, Wolfe C. Seroprevalence and distribution of Flaviviridae togaviridae, and bunya viridae arboviral infections in rural Cameroon adults. Am J Trop Med Hygiene. 2006;74(6):1078-83.

22. Mazaba Uwewe ML, Suaya S, Monze M, Mweene Ndumba L, Masaninoa F, Malama C. First seroprevalence of dengue fever specific immuno globulin $G$ anti-body in western and North West provinces of Zambia a population based cross-sectional study; 2014

23. Himatts OKE, Okoued BDE, Beally ME, Saghalar MA, Elmushaf K. Seroprevalence of dengue infection in the kassala state in the eastern part of Sudan; 2015.

24. Awando JA. Seroprevalence of Anti-Dengue Virus 2 Sero complex Antibodies in out-patients with fever visiting selected hospitals in rural parts of Western Kenya. A cross sectional study. Pan Afr Med J. 2013;73:2010-1.

25. Brunkard JM, López JLR, Ramirez J, Cifuentes E, Stephen J, Rothenberg SJ, et al. Dengue Fever Seroprevalence and Risk Factors, Texas- Mexico Border. Emerg Infect Dis. 2004;13:10.

26. Lenhart A, Orelus N, Maskill R, Alexander N, Streit T, McCall PJ. Insecticidetreated bed nets to control dengue vectors: preliminary evidence from a controlled trial in Haiti. Tropical Med Int Health. 2008;13:56-67.

27. Ananda A, Kuritsky JN, Letson GW, Margolis HS. Dengue Virus Infection in Africa. Emerging Infect Dis. 2011;17:8.

28. Gwer S, Newton CRJC, Berkley JA. Over-diagnosis and co-morbidity of severe malaria in African children: a guide for clinicians. Am J Trop Med Hygiene. 2007;77:6-13.

\section{Publisher's Note}

Springer Nature remains neutral with regard to jurisdictional claims in published maps and institutional affiliations. 